Revista de Economia Política, vol. 32, no 1 (126), pp. 3-20, janeiro-março/2012

\title{
A hipótese do crescimento rápido. Novos argumentos
}

ANTONIO BARROS DE CASTRO*

The hypothesis of fast growth. New arguments. After the 1981-2003 quasi-stagnation, the Brazilian economy signals that it is back to fast growth. The aborted growth spurts in this period accumulated an expansion potential that is now emerging. The growth frustration was particularly significant in the case of the growth surge beginning in 1999, as an outcome of the large 1999 depreciation of the real and the substantial 1990s increase of productivity. Now this repressed growth is being spontaneously liberated. It may be additionally liberated by adequate economic policies. Improvements in macroeconomic policy and the implementation of mini micro reforms are consistent with this incremental approach.

Keywords: quasi-stagnation; fast growth; incremental approach.

JEL Classification: 054.

O presente trabalho deve ser entendido como uma extensão e complementação de "A hipótese do crescimento rápido e sustentável" (Castro, 2004). Este primeiro artigo tem como temas principais a especificidade da "quase estagnação" brasileira de 1981 a 2003, e a experiência contemporânea de diversas economias no tocante à transição para o crescimento rápido e sustentado. Prosseguindo na exploração do tema da passagem para o crescimento rápido, o atual artigo explora a ideia de que os surtos abortados de crescimento ao longo do período 1981-2003 teriam represado um potencial, digamos, adicional de expansão - que não pode, contudo, ser percebido pelos dados disponíveis sobre o desempenho da economia.

\footnotetext{
* Antonio Barros de Castro (1938-2011) foi professor titular de Economia na Universidade Federal do Rio de Janeiro e presidente do BNDES no governo Itamar Franco (1992-93). Este artigo foi escrito em 2005 e restava sem publicação. A Revista de Economia Política, que publicou vários de seus artigos, pública este e, como apêndice, a entrevista que concedeu à Folha de São Paulo, em abril de 2011, sobre o desafio representado pela China - tema a que se dedicou nos últimos anos -, como uma homenagem a esse notável economista e homem público brasileiro.
} 
É também adiantada a hipótese de que o crescimento reprimido ao longo do período de quase estagnação tende a aflorar espontaneamente, uma vez assegurada a estabilidade - mas pode ser acentuado por políticas adequadas a este peculiar contexto. Isto sugere que a economia poderia desde já alcançar um bom ritmo de expansão - o que facilitaria o seu ingresso numa efetiva trajetória de crescimento rápido de longo prazo.

\section{TENDÊNCIAS REVELADAS PELA EVOLUÇÃO DA ECONOMIA BRASILEIRA}

A história contemporânea da economia brasileira é marcada por duas fases, nitidamente diferenciadas. A ruptura ou quebra de tendência verifica-se no entorno de 1980, marcando a transição da primeira (1940-1980) para a segunda fase (19812003). Ao longo da primeira fase, ocorreu a implantação da estrutura produtiva que, em seus traços maiores, caracteriza, até o presente, a economia brasileira. A construção, em quatro décadas, deste amplo e diversificado aparelho produtivo, teve como marco a implantação dos chamados grandes projetos, direta ou indiretamente promovidos por políticas públicas e empresas do Estado. ${ }^{1}$

Mesmo ali onde não se tratava de implantar megaprojetos ou plantas âncora, mas da introdução, por capitais privados, de novos elos nas cadeias produtivas, o avanço se dava ao sabor de projetos, que muitas vezes se mostravam maiores que as empresas incumbidas de levá-los a efeito. ${ }^{2}$ Com o novo tecido econômico sendo constituído, os projetos (antes que os preços relativos) guiavam, em ampla medida, as decisões empresariais - sendo esta uma característica fundamental dessa primeira fase.

Como seria de esperar, os projetos exigiam a absorção massiva de novos conhecimentos. É importante lembrar, no entanto, que este conhecimento em boa medida aqui chegava embutido ou incorporado nos processos que a economia passava a utilizar e nos artigos que ela passa a produzir. A bem dizer, o conhecimento "desincorporado" e operacional evoluía também rapidamente — sem o que não seria possível acionar as novas máquinas e equipamentos. Mas aqui, como em algumas outras experiências contemporâneas de catch $u p$, a produção nem de longe exigia o pleno domínio cognitivo do que estava sendo introduzido no país ${ }^{3}$. Uma segunda característica dessa primeira fase consiste, assim, no notório desequilíbrio entre o conhecimento operacional e o conhecimento formal/científico ${ }^{4}$.

A terceira e última grande característica a ser aqui assinalada se refere ao

\footnotetext{
${ }^{1}$ Ver Castro, 1993.

${ }^{2}$ Devo esta última observação a Aluysio Asti, economista do BNDES.

${ }^{3}$ Amsden (2001).

${ }^{4}$ Uma maneira indireta de se tornar patente esta característica pode ser encontrada num trabalho recentemente divulgado, mostrando que a evolução do PIB se dava, do pós-guerra a 1980, em ritmo
} 
crescimento econômico verificado no período - aí incluídos o seu ritmo (7\%, em média, ao ano), a relativa regularidade do avanço, e o fato de que a expansão era percebida como assegurada. Este último ponto, ou seja, a crença, amplamente compartilhada, na forte vocação da economia para o crescimento (e, neste sentido, na existência de uma "convenção do crescimento") (Castro, 1993), merece um destaque especial. A partir desta perspectiva, o risco de mercado a ser enfrentado pelos investimentos era, genericamente, rebaixado - o que ajudava a tornar o crescimento uma profecia autorrealizada.

Passemos agora à segunda grande tendência que se prolonga por 23 anos: de 1981 a 2003. ${ }^{5}$ Em contraposição à primeira, a segunda fase é marcada pela ausência de grandes projetos, sendo Carajás uma importante exceção. Apesar da escassa alteração, durante esta fase, da estrutura do aparelho produtivo em seu conjunto, intensas mudanças foram introduzidas no âmbito das empresas e no seu relacionamento com os mercados. Como é bem sabido, isto foi impulsionado pela abertura da economia, e por certas consequências da estabilização alcançada mediante o Plano Real. Concretamente, mudaram o gerenciamento e a organização do trabalho, a cesta de produtos ofertada (o que implica, em regra, alterações nos processos produtivos) e, não raro, a estrutura patrimonial das empresas ${ }^{6}$.

A mais importante implicação do que precede é a radical mudança verificada na forma pela qual passa a evoluir a economia. No fundamental, a acumulação de capital e, mais concretamente, a implantação de novos projetos, deixa de ser o eixo em torno ao qual evolui a economia.

Reconhecidamente a economia apresenta, durante o segundo período, e de acordo com os indicadores oficiais, um desempenho pífio, crescendo, em média, algo como $2 \%$ ao ano - vale dizer, pouco mais do que a população. Registram-se, porém, em meio a esta quase estagnação, breves (ainda quando, por vezes, intensos) surtos de crescimento, seguidos de recaídas de magnitude comparável. Por outro lado, a eficiência com que operam as empresas indiscutivelmente avança - o que se traduz tanto em firmes aumentos de produtividade ${ }^{7}$ (e eliminação de empregos), quanto em melhoria/atualização dos produtos levados a mercado. Duas ressalvas devem, no entanto, ser feitas ao que acaba de ser dito.

Primeiramente, as transformações apontadas não se dão ali onde o país dispunha de confortáveis vantagens comparativas (siderurgia e celulose, por exemplo), ${ }^{8}$

muito superior à evolução do capital humano (medido por um índice em que a educação formal tem destacado peso) disponível na economia. Ver Albuquerque, 2004.

${ }^{5}$ Esta longa fase compreende subperíodos, que foram caracterizados pelo autor em "A hipótese do crescimento rápido e sustentado". O presente trabalho deve, aliás, ser entendido como uma extensão e complementação dos argumentos ali apresentados.

${ }^{6}$ Castro (2001), Ferraz, Kupfer e Iootty (2004).

${ }^{7} \mathrm{O}$ aumento da produtividade do trabalho durante os anos 1990 foi extremamente rápido, situando-se entre um mínimo de 5\% (auferido pelas Contas Nacionais) e um máximo de $8 \%$ ao ano (PIM, IBGE).

${ }^{8}$ Coutinho e Ferraz (1994). 
e nem tampouco nas plantas gigantes herdadas do primeiro período (como Camaçari). Além disso, na segunda metade dos anos 1990, algumas novas grandes plantas começam a surgir - alterando antes a geografia econômica que a estrutura setorial da indústria.

A peculiar combinação de medíocres resultados em termos de crescimento médio anual, com intensa transformação do tecido microeconômico (mas não da estrutura produtiva da economia como um todo), dificulta enormemente o trabalho dos analistas. Quando mais não seja, porque o baixo crescimento de forma alguma significava marasmo. ${ }^{9}$ Além disso, porque os indicadores estatísticos disponíveis, voltados para a medição de resultados agregados (macroeconômicos ou setoriais), dificilmente poderiam captar, adequadamente, os efeitos das mudanças em curso. Compreende-se: estas iam se dando, sobretudo, no âmbito das empresas, no seu inter-relacionamento e distribuição espacial.

Como característica marcante do segundo período deve-se ainda destacar a crescente tomada de consciência da peculiar vulnerabilidade a que passou a estar sujeita a economia. É bem verdade que, não obstante carregada de problemas, a economia se mostra capaz de fortes recuperações, ou, mesmo, arrancadas. Mas fica também evidente que estes movimentos não se sustentam. Consequentemente, há que ter cuidados redobrados na interpretação da situação e perspectivas da economia. Trata-se de aproveitar as retomadas, sem acreditar demasiado, por exemplo, nas dimensões de mercado por elas sugeridas. Tampouco há que embarcar facilmente nas oportunidades antevistas a partir do crescente conhecimento daquilo que se pode extrair dos recursos controlados pelas empresas (voltaremos a este ponto).

Em síntese, tudo se passa como se o contexto requeresse que os mercados fossem avaliados com desconto - o que também resulta em parcimônia no aproveitamento do aprendizado adquirido no comando da produção e distribuição de mercadorias. Consegue-se com isto, possivelmente, conter os estragos provocados por desencontros entre demanda e oferta. Mas se este tipo de conduta logra tornar menos frustrante, ou danoso, um contexto caracteristicamente sujeito a golpes (reversões) de demanda, não é menos verdade que ele também ajuda a reduzir o aproveitamento de oportunidades. Ou seja, diminui a aderência da capacidade de produzir à turbulenta evolução da demanda - ao preço da renúncia à exploração de oportunidades que podem se revelar enganosas.

É possível também afirmar que, se na primeira tendência, como anteriormente assinalado, a economia cresce mais do que aprende, na segunda (1980 a 2003), ela aprende mais do que consegue utilizar. Esta proposição veio a ser na prática reforçada pela aceleração, datada dos anos 1980, dos resultados alcançados no campo educacional. Fica assim sugerido que, se a economia puder se livrar das abruptas asfixias de demanda (tarefa precípua da macroeconomia), e, indo além,

\footnotetext{
9 Para uma sumária comparação da modernização dos anos 1990, com o período áureo da industrialização brasileira, ver Castro, 2003.
} 
puder estimular o desrepresamento de oportunidades percebidas, mas não exploradas, a sua trajetória de crescimento poderá ser deslocada para cima.

\section{MELHORISTAS E REFORMISTAS}

Diversas vezes, no curso da segunda tendência, a energia expansiva da economia voltou à tona. A cada retomada seguiu-se, no entanto, após um lapso maior ou menor de tempo, uma abrupta deterioração do ambiente econômico, capaz de anular o movimento expansivo da economia. ${ }^{10}$

A frustração do crescimento parece, no entanto, ter assumido particular importância no caso da recuperação iniciada em 1999. Em parte isto se explica por razões quantitativas. Do primeiro trimestre de 1999 ao primeiro trimestre de 2001, o crescimento acumulado da economia brasileira foi de $8,5 \%$ (4,2\% ao ano). Mas a relevância desta traumática experiência se explica, ainda, por outras razões.

O êxito, penosa, mas rapidamente alcançado, no controle das consequências da temida megadesvalorização, levou muitos a concluir que a estabilidade havia passado por um teste definitivo. A conclusão estava também calcada no fato de que tivera início, na segunda metade de 1998, um sério esforço de ajuste fiscal. Mas o vigor exibido pelo crescimento não era menos impressionante: a expansão, de aproximadamente 20 meses, enfrentou juros reais básicos permanentemente superiores a $10 \%$ ao ano, combinados com um severo esforço de ajuste fiscal.

A impressão de que estávamos diante de algo novo tendia ainda a ganhar força, à medida que os ganhos alcançados pelas empresas nos anos 1990 - que não correspondiam ao esperado, nem pelos defensores, nem pelos críticos da abertura $^{11}$ — iam sendo reconhecidos. Já antes da desvalorização, grande parte da indústria vinha emitindo sinais de que, pelo menos no tocante à produtividade e à luta pelo mercado interno, os desafios colocados pela abertura estavam sendo seriamente enfrentados. ${ }^{12}$ Isso posto, e superada a (breve) turbulência que acompanhou a desvalorização, tornava-se possível pensar mais alto. Não apenas o câmbio oferecia agora uma possível blindagem da economia diante das dificuldades procedentes do exterior, como as exportações, pela primeira vez na história moderna do país, poderiam passar a liderar o crescimento.

O rápido desmoronamento, na transição do primeiro para o segundo trimestre de 2001, do ciclo expansivo iniciado após a desvalorização, contrariou, no entanto, flagrantemente estas suposições. Não discutiremos aqui este traumático episódio. Lembremos apenas que a sorte, no caso, primou pela ausência. À medida que a economia emergia do quase caos da megadesvalorização, e começava (surpreen-

\footnotetext{
${ }^{10}$ Castro (2004) examina o impulso expansivo e a especificidade adquiridos pela economia brasileira, em decorrência dos 23 anos de quase estagnação.

${ }^{11}$ Castro (1999).

${ }^{12}$ McKinsey (1998).
} 
dentemente) a crescer, a Argentina, segundo maior parceiro comercial do Brasil, aproximava-se do virtual colapso, enquanto a bolsa de valores de Nova York emitia sinais mais que inquietantes. ${ }^{13} \mathrm{E}$, como se não bastasse, em março de 2001 é subitamente anunciada a chegada de uma grave crise energética, insuspeitada entre não especialistas, e que tornava o futuro, na melhor das hipóteses, opaco.

O ciclo abortado em 2001 veio alimentar o debate acerca do estado da economia - e de como ela deve ser tratada. Veio, inclusive, a fornecer argumentos para posições antagônicas a este último respeito.

De acordo com uma posição, daqui por diante referida como "melhorista", teria ficado claro que, consolidadas a estabilidade monetária e a abertura, e adotado o novo regime de políticas macroeconômicas (o tripé política fiscal severa, câmbio flutuante e metas inflacionárias), a economia podia voltar a crescer sustentadamente. A experiência vivida após a desvalorização de 1999 apontava nesta direção - mas também deixava clara a vulnerabilidade da economia perante choques. Haveria, portanto, que gerenciar a economia com muita cautela. Quando mais não seja, porque as sucessivas crises do final dos anos 1990 acarretaram o explosivo crescimento da dívida pública, bem como o encurtamento e dolarização de uma crescente proporção das obrigações. Consequentemente, o câmbio flutuante (um para-choque em frente aos distúrbios externos) passara a operar como uma ameaça a mais para a solvência fiscal. ${ }^{14}$ Havia, em suma, que tornar ostensivo o comprometimento com a solvência fiscal - o que veio a ser supostamente alcançado, com a Lei de Responsabilidade Fiscal, de maio de 2000. ${ }^{15}$

Ou seja, a desvalorização e os substanciais ajustes verificados no plano fiscal haviam retirado a economia da borda do precipício, tornando o crescimento sustentado uma possibilidade. Mas a consolidação do novo quadro requeria muita prudência e o incessante aprimoramento do clima de negócios. Seria também recomendável que as instituições locais fossem aproximadas do benchmark internacional. Afinal, a turbulência a que permaneceu exposta a economia por tantos anos havia deixado como herança não apenas um clima de stress (e uma notória volatilidade das expectativas), como uma entranhada desconfiança de tudo o que é típico ou local.

Mas a fronteira das melhorias poderia ir além do acima sugerido. O câmbio flutuante poderia ser discretamente monitorado (visando amenizar ou conter movimentos especulativos), enquanto o sistema de metas poderia ser, talvez, em alguma medida, flexibilizado - desde que isto não comprometesse sua capacidade de coordenar expectativas. Além disso, as fases de vigor expansivo poderiam ser apro-

\footnotetext{
${ }^{13}$ Para um provocativo exame da crise de 2001, ver Faria, 2003.

${ }^{14}$ A proporção dolarizada da Dívida Pública Total (inclusive swaps) atingiu 50\% em junho de 2002, e se manteve acima de $50 \%$ até fevereiro de 2003. Cabe, no entanto, chamar a atenção para o fato de que já em novembro de 2004 o total da dívida pública corrigida pelo câmbio havia baixado para $25 \%$.

${ }^{15}$ Sobre as condições em que se dá a construção das novas instituições fiscais, aí incluída a Lei de Responsabilidade Fiscal, ver Loureiro e Abrucio, 2004.
} 
veitadas para que o país começasse a fazer políticas fiscais compensatórias - abandonando, com isso, o comportamento pró-cíclico das políticas públicas, datado, pelo menos, da chamada crise do Tequila (1994-1995).

Dois aspectos devem ainda ser acrescentados à visão melhorista que estamos caracterizando. Primeiramente, a ênfase no aperfeiçoamento da gestão macroeconômica e na implementação de minirreformas de caráter microeconômico reflete uma abordagem incrementalista. Convém ressaltar que a mesma atitude deveria ser estendida ao campo institucional: antes que novos parâmetros ou mudanças no regime de política econômica haveria que introduzir, passo a passo, alterações na legislação e na regulação, destinadas a desembaraçar o comportamento dos atores econômicos. ${ }^{16}$

Além disso, cabe chamar a atenção para a atitude ante ao crescimento - terreno onde é possível perceber a existência de diferenças entre os melhoristas. Para entendê-lo convém partir da premissa de que todos buscam o crescimento inflacionariamente neutro, ou seja, aquele que não desperta pressões inflacionárias. Os mais prudentes ou conservadores incorrem, no entanto, a este propósito, em dificuldades. Isso porque, para eles, os limites do crescimento (no sentido do ritmo de expansão que preserva a estabilidade) devem ser apreendidos, mediante observação do ocorrido no passado. Em outras palavras, por métodos estatísticos, ou mediante o ajuste de funções de produção, buscarão eles verificar a que taxas pode crescer a economia, à luz da experiência pregressa. Isso, no entanto, destoa patentemente da própria essência da posição melhorista, que pretende não apenas superar o passado, como avançar mediante o aperfeiçoamento do presente. Conflita, ainda, com a ideia - realçada na primeira parte deste trabalho — de que o passado compreende duas tendências e com a suposição, mais adiante comentada, de que pode estar em curso, na atualidade, uma nova ruptura de tendência. ${ }^{17}$

À posição, notoriamente conservadora, que acaba de ser evocada, ${ }^{18}$ opõem-se, entre os próprios melhoristas, aqueles que creem que é possível identificar falhas de mercado, a serem corrigidas mediante políticas ativas. Isto implica dizer que o melhorismo pode comportar a adoção de políticas industriais destinadas a disseminar ou fortalecer condutas inovadoras. Bastaria admitir, para tanto, que as em-

\footnotetext{
${ }^{16}$ Uma ampla apresentação da posição aqui referida como melhorista pode ser encontrada no documento do Ministério da Fazenda "Consolidando a Estabilidade Macroeconômica", de novembro de 2004, cujo conteúdo, como é fácil verificar, vai muito além dos temas diretamente relacionados com a consolidação da estabilidade.

${ }^{17}$ Guiar-se fundamentalmente pelas tendências passadas, sem ter em conta as transformações recentemente ocorridas, talvez ajude a explicar erros de previsão no tocante ao comportamento esperado da economia. Um possível (e importante) caso seria o da estimativa, pelo Banco Central, de um crescimento de 3,5\% para a economia brasileira em 2004 (Relatório de Inflação, dezembro de 2003).

${ }^{18}$ Haveria que assinalar a existência, entre os melhoristas, de sérias discordâncias no tocante ao ritmo a que a inflação deve ser reduzida. Cabe também deixar claro que o melhorismo, numa versão ampla do conceito, inclui severos críticos da condução das políticas públicas, especialmente no campo da política macroeconômica.
} 
presas não se mostram capazes de apropriar-se de todas as vantagens derivadas das inovações - proposição válida para qualquer tipo de economia de mercado.

Voltemo-nos agora para as posições que discrepam do melhorismo - e que serão aqui, tão somente, sumariamente referidas. Sua característica comum é a crença em que, sem profundas reformas, a economia brasileira não se mostra capaz de alcançar o crescimento sustentável. Os problemas da economia residiriam, em suma, na própria estrutura da economia, ou no chamado modelo de política econômica - e não na condução dada à política econômica. A longa estagnação, os sucessivos tombos da economia, e problemas tais como os juros reais cronicamente elevadíssimos, são apontados, nesta perspectiva, como algumas das dificuldades a serem superadas mediante reformas. A experiência internacional (contrastes com casos exitosos, como Coreia e Chile, bem como outros sujeitos a crises recorrentes) é frequentemente invocada neste tipo de posicionamento para reforçar a defesa de profundas mudanças.

O reformismo (referido aqui, fundamentalmente, ao tema da retomada sustentável do crescimento) comporta, no entanto, atitudes francamente antagônicas. De um lado estão posicionados aqueles que creem que a revisão das reformas levadas a efeito na década dos 1990, bem como do atual modelo de gestão macroeconômica, e o restabelecimento de certos controles (especialmente no que toca à liberdade de trânsito dos fluxos financeiros), são condições para que a economia volte a crescer sustentadamente. ${ }^{19}$ No polo oposto situam-se aqueles que pregam o aprofundamento das reformas pró-mercado - e a minimização das interferências políticas de qualquer natureza. ${ }^{20}$

Contra o pano de fundo da sumária esquematização realizada neste item, começaremos, no que segue, a refletir sobre o crescimento além da "atual" retomada.

\section{A LIBERAÇÃO DO POTENCIAL DE CRESCIMENTO}

Diversos analistas já assinalaram o fato de que, numa economia sujeita a repetidas crises, o conhecimento é canalizado para atividades percebidas como de baixo risco e, em última análise, destinadas a garantir a sobrevivência. ${ }^{21}$ Não nos parece, contudo, que as implicações desta família de condutas para o (possível) crescimento ulterior da economia tenham sido jamais exploradas. Mais que isto: para que a ideia venha a ser incorporada ao debate, parece-nos importante uma breve reflexão sobre o crescimento econômico, com destaque para os seus fundamentos microeconômicos.

À medida que uma economia passa a contar com empresas com algum grau de amadurecimento, ou seja, que já acumularam não apenas recursos materiais,

\footnotetext{
${ }^{19}$ Mercadante (1998), De Paula (2003).

${ }^{20} \mathrm{O}$ essencial desta posição pode ser encontrado em Arida, Bacha e Lara-Resende (2004).

${ }^{21}$ O tema é extensivamente tratado em Ruiz, 1994.
} 
como conhecimentos e capacitações especializadas, seu crescimento vai depender do aproveitamento, mais ou menos intenso e criativo, de tudo aquilo que elas controlam. Em tais condições, adquire grande importância o princípio segundo o qual uma empresa é um conjunto complexo de recursos (aí incluídos, cabe insistir, os conhecimentos), onde sempre há carências (ou gargalos) e sobras. Mais concretamente, a qualquer momento, alguns recursos encontram-se plenamente utilizados, ou até mesmo sobreutilizados, enquanto outros se encontram subaproveitados. $\mathrm{O}$ crescimento passa então a ser, em boa medida, o resultado da remoção de gargalos e do maior (e melhor) aproveitamento de sobras..$^{22}$ Este quadro difere, no entanto, qualitativamente, daquele característico do catch up clássico, em que, conforme mencionado no início deste trabalho, os projetos (direta ou indiretamente procedentes da esfera pública) excedem, de muito, a experiência das empresas.

Duas ponderações devem ser acrescentadas ao que precede. Se o crescimento já era, no pós-guerra (e nas economias avançadas), em boa medida, um incessante processo de reaproveitamento de capacitações e recursos, com mais razão isto se tornou verdadeiro, contemporaneamente, dada a flexibilidade das novas tecnologias, e o imenso potencial de diferenciação de produtos daí decorrente. ${ }^{23} \mathrm{Em}$ tais condições surgem novas possibilidades no tocante à relação entre crescimento e acumulação de capital.

Tendo em conta o que acaba de ser dito, compreende-se que uma economia sujeita a repetidas frustrações de demanda é um meio ambiente em que diversas possibilidades de desengargalamento e de aproveitamento de capacidades sobrantes foram (e, possivelmente, continuam a ser) percebidas pelas empresas, sem que surjam condições propícias ao seu aproveitamento. Se assim é, a difundida noção de que no período 1980-2003 as empresas se valiam, predominantemente, de estratégias defensivas, está mal formulada. As empresas, especialmente no campo industrial, mudaram intensamente ao longo do período - e isto já é um indício de que buscaram, intensamente, novos posicionamentos.

Ocorre, porém, que mudaram, mas não exploraram as possibilidades complementares entreabertas pelas próprias mudanças. Limitaram ou contiveram, com isto, por exemplo, a adoção de novos equipamentos, de novos processos - e o próprio aprendizado daí derivado. Ou seja, as novidades não chegaram a ser plenamente aproveitadas. Afinal, com os avanços sendo logo interrompidos por retração das expectativas, dificilmente se chegou a operar sob a - usualmente fértil pressão da demanda. Em tais condições, mesmo nos casos de mudança exitosa, raramente se mostrou necessário experimentar, por exemplo, mais de um turno de

\footnotetext{
${ }^{22} \mathrm{O}$ acima dito assumidamente provém de Penrose (1959), para a qual o crescimento da firma depende da extração de novos serviços dos recursos nela existentes.

${ }^{23}$ Não se trata de que o custo e a escala não mais contem. Especialmente no que concerne à base (por vezes referida como plataforma) dos produtos crescentemente complexos e diferenciados que vão sendo lançados no mercado, a escala ainda é fundamental. Mas ela não prevalece como arma da competição, ali onde se briga pela preferência dos consumidores.
} 
produção, o que tende a deter, precocemente, o encadeamento das mudanças - e limita o aprendizado a elas associado. Recentemente, o bem-sucedido reposicionamento de numerosas empresas em direção ao mercado externo veio a tornar ainda mais amplo e importante o fenômeno das oportunidades antevistas, mas não (ainda) devidamente exploradas.

As consequências do anterior certamente não são triviais. Para percebê-lo convém voltar a adotar uma visão agregativa, e considerar (por contraste) o caso de uma economia que não passou por sucessivas asfixias de demanda, e no qual não se verificou, recentemente (inclusive por parte de empresas há muito maduras) a descoberta de amplas oportunidades no mercado externo. Numa economia deste tipo - ou seja, normal —, o uso da capacidade, num dado momento, pode ser, ou não, considerado pleno. Quando se encontra significativamente abaixo, diz-se que a utilização da capacidade poderá ser ampliada por medidas de estímulo à demanda efetiva. E é bastante plausível supor, nestes casos, tanto que o aumento da demanda será respondido pelo maior uso da capacidade instalada, quanto que o crescimento daí resultante será "inflacionariamente neutro". ${ }^{24}$

A situação é, porém, muito diferente numa economia como a brasileira, na quadra atual. Nela, seguramente, até mesmo possibilidades de rebaixamento de custos foram visualizas como possibilidades, sem ser, no entanto, exploradas. Há, então, como já foi sugerido, uma situação de subaproveitamento da própria capacidade de aprender. Cuidado, porém: não se trata de uma situação de baixo aprendizado. Houve muita mudança, naturalmente acompanhada de experimentação e aprendizado. O que cabe, no entanto, afirmar é que durante o período em questão, a economia aprendeu mais do que usou - o que equivale a dizer que acumulou quase capacitações. ${ }^{25}$ Sob este prisma, estamos, pois, aqui, na situação inversa à do catch up, onde, como assinalado no início deste artigo, usava-se mais do que se aprendia.

\section{O CRESCIMENTO ALÉM DA RETOMADA}

O debate sobre o crescimento da economia brasileira tem evoluído rapidamente. Até meados de 2004, muitos teimavam em não reconhecer, sequer, que a economia se encontrava em expansão. À medida, porém, que este juízo acerca do estado da economia passou a ser claramente negado pelos dados, muitos tenderam a refluir para um posicionamento mais genérico: a expansão não teria como sustentar-se.

\footnotetext{
${ }^{24}$ Ali onde a evolução da economia vem se dando de forma regular, não parece ser grave ignorar o fato de que a folga agregada de capacidade é um conceito discutível - e que a dinâmica do crescimento conta, sempre, com a cadeia de gargalos e sobras percebidos pelas empresas.

${ }^{25}$ Para uma abordagem centrada na evolução das capacitações do tipo aqui empregado, ver Langlois, 2004. Parte-se, nesta perspectiva, da ideia de que o mundo da produção possui informações e conhecimentos imperfeitos, diferenciado segundo empresas, sendo limitado o valor das fórmulas gerais (blueprints).
} 
Enquanto isso, para os que já percebiam, há algum tempo, que a economia se encontrava em crescimento (num movimento mais vigoroso do que aquele que teve início após a desvalorização de 1999), ${ }^{26}$ novas questões iam se colocando.

Para um grupo, trata-se de estabelecer, à luz das informações disponíveis sobre o desempenho da economia, o ritmo a que ela poderia sustentadamente crescer. Em outras palavras, haveria que descobrir, por métodos consagrados de aferição, a taxa a que poderia crescer o PIB, dito potencial, da economia. Para outros, críticos da postura anterior (e convencidos de que a ruptura em curso estaria introduzindo novos parâmetros e tendências), tratava-se, prioritariamente, de entender e caracterizar os traços maiores do surpreendente desempenho recente da economia. ${ }^{27}$ Compreende-se: são incontáveis os erros de avaliação cometidos, aqui e no exterior, a esse respeito. Indiscutivelmente, porém, o ideal seria ir além. Para tanto, faltam, porém, informações, não apenas sobre o potencial reprimido de crescimento, como sobre as novas tendências espontaneamente emergentes à medida que avança a ruptura. Pouco se conhece, além disso, das instituições e, sobretudo, das políticas que virão a respaldar o novo padrão de crescimento - ainda quando se possa desde já afirmar que o atual governo tem-se revelado particularmente fértil na criação de instituições capazes de melhorar o ambiente de negócios. ${ }^{28}$ É neste contexto, e como primeiríssima aproximação, que devem ser entendidas as reflexões que se seguem.

Continua em curso o crescimento mediante ocupação de capacidade - a qual vem sendo, presumivelmente, não apenas mais intensamente explorada, como (re) aproveitada de acordo com oportunidades antevistas no passado, mas não devidamente exploradas. Este tipo de crescimento, onde está fortemente presente a desrepressão de oportunidades, ajudaria, aliás, a explicar o fato de que a demanda por máquinas e equipamentos (mas não o investimento em novas plantas) venha aumentando acima do que seria de esperar no início de um ciclo expansivo. Com efeito, o consumo aparente de bens de capital cresceu 14,2\% em 2004 (até o terceiro trimestre, e comparado com igual período do ano anterior).

Por outro lado, ainda quando seja bastante elevado o nível de ocupação de capacidade em insumos básicos, bem como o atraso acumulado no tocante à infraestrutura, não é de esperar o surgimento, na atual fase de retomada, de um grande volume de investimento nestas áreas. Em insumos básicos, porque ali onde existem vantagens comparativas reveladas, não há por que verificar-se o represamento de oportunidades. Já em infraestrutura, porque os projetos são, reconhecidamente, de

\footnotetext{
${ }^{26} \mathrm{Na}$ Carta de Conjuntura do Instituto de Economia da UFRJ, especialmente através dos artigos de Caio Prates, pode ser encontrada uma cobertura, passo a passo, das duas últimas grandes retomadas: a que se estende de maio-junho de 1999 a março de 2001; e a que teve início no terceiro trimestre de 2003.

${ }^{27}$ Um esforço nesta direção foi feito em Castro, 2004.

${ }^{28}$ Caberia aqui destacar, entre as mais recentes mudanças, as medidas de desoneração do investimento, a nova Lei de Inovação, a nova Lei de Falência e a regulamentação das PPP.
} 
longa maturação - e altamente sensíveis às incertezas inerentes às indispensáveis mudanças de regulação.

Ainda no que toca aos investimentos, cabe destacar que a sua definição (em outros campos que não insumos básicos e infraestrutura) começa agora a ter por base a formulação de novas estratégias de afirmação por parte das empresas. Isto, evidentemente, discrepa substancialmente do ocorrido na fase heroica da industrialização (1940-1980), quando os projetos — destinados a fazer avançar a estrutura industrial do país - tinham óbvia precedência sobre a estratégia das empresas.

A segunda conjectura, quase um corolário da primeira, consiste na não necessidade de promover, desde a retomada, um salto no montante global de investimentos. Afinal, e como já deve estar claro, a fase inicial do crescimento, no quadro em foco, em mais de um sentido se baseia no maior e melhor aproveitamento do preexistente.

$\mathrm{Na}$ medida em que procedam as ponderações que acabam de ser feitas, fica sugerida a existência de uma fase ou período, suponhamos, de dois a quatro anos, de transição para o crescimento propriamente dito. Duas observações devem ser aqui introduzidas.

Durante a fase inicial de expansão, a relação entre investimento e crescimento se caracterizaria pela prevalência do último sobre o primeiro. Ou seja, o crescimento faria aflorar o investimento - e só mais tarde se afirmaria a relação usual em que o investimento precede (e, simplificadamente, determina) o crescimento.

Cabe ainda observar que, dada a suposta precedência do crescimento sobre o investimento, o curto prazo deve ser entendido, neste singular contexto, como estratégico. Isto, obviamente, se choca com o emprego usual deste termo: reserva-se, em regra, a denominação de estratégico para o longo prazo, sendo tática o termo (e conceito) associado ao curto prazo. Aqui, porém, o curto prazo deve ser entendido como estratégico — no sentido de condição para a efetivação da ruptura, com transição para um novo quadro.

A propósito do que acaba de ser dito, cabe insistir em que o investimento simplesmente não pode dar partida no crescimento. Entende-se: o consumo encontra-se notoriamente comprimido e deve aumentar, digamos, ao ritmo do PIB. Por outro lado, nem o atual governo, nem o público em geral aceitariam que o país voltasse a recorrer pesadamente à poupança externa (Déficit de Transações Correntes). Em suma, só paulatinamente o país poderá voltar a contar com uma "máquina de crescer" — que supõe reforço e adaptação da capacidade de financiamento, intensificação da geração de intangíveis, recuperação da engenharia, e outros requisitos. Esta é, aliás, mais uma forma de se perceber a importância decisiva de se aproveitar, na transição para o crescimento de longo prazo, o potencial contido nas empresas - e de se entender que o curto prazo é, nestas circunstâncias, estratégico.

$\mathrm{Na}$ medida em que estiverem certas estas suposições, a situação poderá avançar, substancialmente, se se souber tirar proveito do potencial oculto no quadro atual. Evidentemente, o apoio à inovação, em suas múltiplas formas, poderia ter aqui uma grande importância - o que traz para o primeiro plano a importância do concertamento entre interesses privados e públicos, no esforço de fazer aflorar as possibilidades dormentes nas empresas. 
A agenda que assim começa a se esboçar seria seguramente facilitada na medida em que fossem superadas duas obsessões: a de negar o passado e a de fazer o “dever de casa", copiando o existente no exterior. Quanto a este último ponto, cabe deixar claro que as melhorias de meio ambiente são muito bem-vindas, sempre e quando - usando uma velha expressão inglesa — retirem areia das rodas da indústria. ${ }^{29}$ Não fazem, contudo, sentido, reformas cuja assimilação poderia colocar em risco a retomada - e a original transição para o crescimento sustentado que parece estar, neste momento, se delineando.

Como se depreende de tudo o que precede, a presente situação da economia brasileira pode ser sumariamente concebida como o início de superação de uma longa crise, à qual de múltiplas maneiras (já) se resistiu, e cujo custo já foi em grande medida pago. Em outras palavras: o dinamismo atual (esboçado, pioneiramente, no ciclo abortado de 1999-2001) sugere que as tendências prevalecentes a partir de 1980 podem haver sido - a duras penas — derrotadas. É desnecessário insistir em que esta perspectiva discrepa frontalmente daquela que crê que a retomada do crescimento sustentado supõe, mais uma vez, a refundação da economia.

\section{CHINA, "FÁBRICA DO MUNDO”}

Dentre os problemas que o crescimento desta economia tem pela frente, um apenas será aqui referido. Dada a ascensão fulgurante da China como potência manufatureira, como plataforma de multinacionais, e base de agressivas empresas locais (muitas delas pertencentes a entidades públicas), há que admitir que diversas opções feitas neste país - em termos setoriais, tecnológicos e de produtos, hoje se revelam "erradas". Em outras palavras, tais escolhas não teriam sido feitas — ou teriam tomado outros rumos — se se soubesse de antemão que teríamos que concorrer com o rolo compressor das empresas que vieram a florescer nos últimos dez a quinze anos naquele país-continente. A bem dizer, a emergência da economia chinesa como "fábrica do mundo" coloca em questão um dos trunfos da economia brasileira, vis-à-vis o resto da América Latina. Referimo-nos ao fato de que esta foi a única economia que suportou a (e valeu-se da) abertura, mantendo e revitalizando uma estrutura industrial altamente diversificada. Arranhando apenas a superfície desta nova e fundamental questão, acrescentaríamos dois comentários.

Tendo escapado à especialização por setores e funções (a indústria automobilística na Argentina, por exemplo, tornou-se apenas montadora), a indústria brasileira estaria sendo hoje, possivelmente, forçada a especializar-se. Referimo-nos aqui, porém, à especialização por produtos. ${ }^{30}$ Este tipo de especialização não poderia ter ocorrido por ocasião da fuga desordenada para a frente (em busca da moderniza-

\footnotetext{
${ }^{29} \mathrm{O}$ mesmo pode ser dito de reformas que tornem mais leve e bem distribuída a carga fiscal.

${ }^{30}$ Exemplificando: aviões regionais, carros compactos, motores elétricos, máquinas agrícolas, moda de praia, toalhas de qualidade superior, calçados femininos, álcool etc.
} 
ção) promovida pela abertura dos anos 1990 . Hoje, contudo, tendo sido preservadas, em boa medida, as cadeias produtivas (ressalvadas conhecidas exceções), esta é uma possibilidade que já vem sendo explorada por diferentes empresas. Trata-se de um tipo de especialização a muitos títulos superior, e amplamente verificado entre as economias desenvolvidas. Trata-se, também, de um movimento particularmente adequado ou fértil para o florescimento de inovações. ${ }^{31}$ Para tanto, a política industrial deveria, porém, ser repensada e, seguramente, reforçada. Por outro lado, esta é mais uma razão pela qual a partida para o crescimento via investimento deva ser entendida não apenas como difícil (como anteriormente assinalado) mas possivelmente como inadequado, dada a cristalização precoce de escolhas a serem posteriormente revistas (sunk costs).

Em suma, não há como negar que nos encontramos, neste momento, do ponto de vista manufatureiro, em rota de colisão com a China. E isto leva a reafirmar que as políticas de apoio ao crescimento devem ser reforçadas por políticas de redirecionamento e, digamos, especialização avançada de capacitações.

Para encerrar o que veio a exceder, de longe, a proposta inicial - acrescento um par de comentários sobre o primeiro governo do presidente Inácio Lula da Silva. Foi observado em outro trabalho ${ }^{32}$ que este governo mostrou-se capaz de levar adiante, e estender para novas áreas, o pragmatismo que despontou (mas manteve-se restrito a certos espaços) no segundo governo FHC. A bem dizer, o que estamos chamando de abordagem pragmática - no sentido de ser sensível à especificidade do contexto - não chegou a todas as áreas. A política monetária, por exemplo, ostenta uma rigidez que, se por um lado reflete a prudência imposta pelo passado inflacionário deste país, por outro parece ignorar que estamos apenas emergindo de uma longa fase de sistemática inibição de iniciativas na esfera produtiva, tanto por parte das empresas como por parte das instituições públicas voltadas para o apoio ao desenvolvimento.

Não obstante a contradição que acaba de ser assinalada, é impossível negar que este foi um governo eminentemente aberto à negociação. Aliás, e de acordo com um dos fundadores do PT, isto não deveria surpreender, porque a negociação "está no DNA" do partido hegemônico no atual governo. ${ }^{33}$

Se o pragmatismo tem uma sólida raiz plantada na experiência sindical/negociadora, não é menos verdade que a experiência acumulada na administração de cidades, berço da experiência de governo do PT, seguramente reforçou o enfoque realista e, digamos, enviesado para a administração. Vista a questão por um outro ângulo, tudo isto ajudou a abandonar o mito fundacionista característico da es-

\footnotetext{
${ }^{31}$ A experiência recente do México mostra, aliás, que a especialização por funções (do tipo atividades altamente empregadoras de mão de obra) é das mais vulneráveis à atração chinesa.

${ }^{32}$ Castro (2004).

${ }^{33}$ Diversos depoimentos poderiam ser reunidos, apontando na mesma direção. Recentemente tive ocasião de ouvir de um reconhecido líder da indústria que os empresários "tinham uma interlocução com o governo que raramente foi alcançada”.
} 
querda tradicional. E é a partir desta bagagem que o primeiro governo Lula - ou, pelo menos, uma parte importante dele - se dedicou a ganhar a confiança do empresário nacional. Em suma, este, como o governo anterior, cultivou a confiança dos detentores de capital, mas esta administração — ajudada sem dúvida pelo excepcional desempenho do Balanço de Transações Correntes - tem revelado uma particular disposição para ouvir e colaborar com as empresas, especialmente as de propriedade nacional. Além disso, o presente governo indiscutivelmente estende a sua postura aberta à negociação a todos os interesses organizados e movimentos sociais. Tudo isso colabora para o surgimento de um clima de trégua entre o setor privado e o setor público, que fortemente difere do ocorrido nos anos 1990. ${ }^{34}$

\section{REFERÊNCIAS BIBLIOGRÁFICAS}

ALBUQUERQUE, Roberto Cavalcanti (2004) “A questão social no Brasil. Um balanço do século XX. Apresentação no "Seminário Especial do IPEA, setembro.

AMSDEN, Alice (2001) The Rise of the Rest. Challenges to the West from Late-Industrializing Economies. Oxford: Oxford University Press.

ARIDA, Pérsio, Edmar BACHA e André LARA-RESENDE (2004) High Interest Rate in Brazil: Conjectures on the Jurisdicional Uncertainty. Mimeo.

CASTRO, Antonio Barros de (1993) "Renegade development: rise and demise of state led development in Brazil”, em Smith, W. (org.), Democracy, Markets and Structural Reforms in Latin America. New Jersey: Transaction Publishers.

CASTRO, Antonio Barros (1999) “O lado real do Real: O debate e algumas surpresas”, em Magalhães, João Paulo de Almeida, Ademar Mineiro e Luiz Antonio Elias. (orgs.), Vinte Anos de Política Econômica. Rio de Janeiro: Contraponto, 1999.

CASTRO, Antonio Barros de (2001) “A reestruturação da indústria brasileira nos anos 90: Uma interpretação”, Revista de Economia Política, 21 (3): 3-26.

CASTRO, Antonio Barros de (2003) "El segundo catch up brasileño. Características y limitaciones", Revista de la CEPAL, 80: 73-83.

CASTRO, Antonio Barros de (2004) “A hipótese do crescimento rápido e sustentável”, em Velloso, João Paulo dos Reis (org.) Rio de Janeiro: José Olympio Editora, no prelo.

COUTINHO, Luciano e João Carlos FERRAZ (coord.) (1994) Estudo da Competitividade Industrial da Industria Brasileira. Campinas: MCT- Editora da Unicamp.

FARIA, Lauro Vieira (2003) "Financial markets, external shocks and policy responses: The case of Brazil 2001. Revista de Economia Política, 23 (4): 43-57.

FERRAZ, J. Carlos, David KUPFER e Mariana IOOTTY (2004) "Competitividad industrial en Brasil 10 años despuesde la liberación”, Revista de la CEPAL, 82: 91-119.

LANGLOIS, Richard (2004) Chandler in a Larger Frame: Markets, Transaction Costs, and Organizational Form in History, University of Connecticut. Mimeo.

LOUREIRO, Maria Rita e Fernando ABRÚCIO (2004) "Política e reformas fiscais no Brasil recente", Revista de Economia Politica, 24 (1): 50-72.

MCKINSEY Global Institute (1998) Productivity, The Key to an Accelerated Development in Brazil.

MERCADANTE, Aloizio (org.) (1998) O Brasil pós-Real: a política econômica em debate. Campinas: IE - Unicamp.

\footnotetext{
${ }^{34}$ Sobre a evolução das políticas de apoio ao crescimento, de uma concepção centrada no primado dos instrumentos para uma abordagem centrada na colaboração, ver Rodrik, 2005.
} 
DE PAUlA, João Antonio (org.) (2003) A Economia Política da Mudança. Desafios e Equívocos do Início do Governo Lula. Belo Horizonte: Autêntica Editora.

PENROSE, Edith (1959) The Theory of the Growth of the Firm. Oxford: Oxford University Press.

RODRIK, Dani (2005) Industrial Policy for the Twenty-First Century. Mimeo.

RUIZ, Ricardo Machado (1994) Estratégia Empresarial e Reestruturação Industrial (1980-1992): Um

Estudo de Grupos Econômicos. Unicamp, Instituto de Economia.

\section{APÊNDICE}

\section{BRASIL TEM DE SE REINVENTAR PARA TRATAR COM A CHINA, DIZ ANTONIO DE CASTRO}

\section{Entrevista concedida por Antonio Barros de Castro a Claudia Antunes, Folha de S. Paulo, 11 de abril de 2011}

O Brasil tem de se reinventar para ser bem-sucedido em uma economia mundial radicalmente mudada pela China, diz o economista Antonio Barros de Castro. Diante da competição chinesa, afirma ele, não adianta proteger setores industriais para que eles fiquem "um pouco mais sofisticados", como se fez no passado, porque os asiáticos fazem o mesmo com maior velocidade. "Mesmo se o câmbio e o custo Brasil forem neutros, boa parte da indústria brasileira não é competitiva porque o sistema industrial chinês é mais eficiente." Barros de Castro diz que o Brasil deve aproveitar a "trégua" oferecida pelo boom de matérias-primas para desenvolver produtos originais, como plástico de álcool e aços especiais usados na exploração de petróleo.

Folha - O sr. vem estudando as mudanças provocadas pela China. Qual a conclusão?

Antonio Barros de Castro - Há seis anos eu comecei a suspeitar que a emergência chinesa representava uma ruptura na trajetória do sistema econômico mundial. Não se tratou de uma mudança só de tamanho, de aumento do peso do país.

\section{Que ruptura é essa?}

Antonio Barros de Castro - Nos anos 50, o economista alemão Hans Singer sintetizou assim o dilema da época: "Países industrializados têm o melhor de dois mundos, como consumidores de produtos primários e produtores de manufaturados, enquanto os subdesenvolvidos têm o pior, como consumidores de manufaturas e produtores de matérias-primas".

Ele se baseava na tendência de queda dos preços das matérias-primas, enquanto os dos industrializados ficavam iguais ou subiam.

Com a ascensão do leste asiático, capitaneada pela China, isso virou de pernas para o ar. Países mais atrasados compram manufaturados baratos e exportam matérias-primas cada vez mais caras. Angola, por exemplo, cresce a $15 \%$ ao ano. É um movimento tectônico.

Mas o Brasil teme a desindustrialização. Como o país pode se adaptar a isso? Há exemplos bem-sucedidos?

Antonio Barros de Castro - As realidades são diferentes. Uma parte da Ásia evoluiu com a China e não enfrenta os mesmos dilemas enfrentados pelo Brasil.

Outro bloco já havia se especializado na exportação de matérias-primas, incluindo latino-americanos como o Chile. Agora, os clientes pagam melhor, mas historicamente esse caminho tende a ser visto como maldito. 
Estados Unidos, Alemanha e Japão ainda podem ser dinâmicos combinando capacidade alta de inovação com a vigilância de seus direitos de propriedade intelectual. Já o Brasil é um híbrido industrial e agrícola.

\section{Mas só o lado agrícola continua competitivo. Por quê?}

Antonio Barros de Castro - Nos anos 90 e no início deste século, a indústria brasileira se preparou para competir com os produtos dos EUA e da Europa. Conseguiu bons resultados, basta ver o crescimento das exportações de bens duráveis, como carros e eletrodomésticos, entre 2003 e 2005. Mas durou pouco. As exportações de produtos primários foram de 30\% do total em 2004 para $44 \%$ em 2010, e as de manufaturas caíram de $57 \%$ para $43 \%$.

Isso ocorreu porque a competição deixou de ser com EUA e Europa e passou a ser com o sistema comandado pela China. Atualmente, um país como o Brasil, que no novo contexto tem vantagens máximas no setor primário e mínimas no industrial, tem que se reinventar.

\section{Como?}

Antonio Barros de Castro - Falando de maneira simplificada, temos duas opções. A primeira é proteger a indústria que existe, tentando agregar valor às cadeias de produção, completando-as e sofisticando-as. Foi o caminho entre 1950 e 1980.

Mas havia a premissa, correta na época, de que as economias mais avançadas eram tecnologicamente maduras e tinham crescimento lento da produtividade. Tratava-se de fechar um hiato, atingir um nível em que nossos concorrentes estavam mais ou menos parados ou evoluíam devagar.

Essa premissa hoje não existe mais. Nossos concorrentes ainda estão amadurecendo, estão alcançando novos patamares de produtividade e agora aumentando o esforço tecnológico para acelerar sua eficiência.

A China busca produtos menos poluentes, verdes. Está exportando fábricas para países vizinhos e deslocando outras para sua região oeste, com mão de obra mais barata. É o que chamo de China 2.

A China 1 é a do "made in China" (fabricado na China), e eles deram uma surra baseada em trabalho barato e em imitação tecnológica. A China 2 quer ser a do "created in China" (criado na China).

Portanto, o ataque vem de baixo. Só faz sentido reforçar aquilo em que temos chance de correr mais rápido do que eles, que é a nossa segunda opção. O resto tem que ser redirecionado ou desaparecer.

\section{E temos tempo?}

Antonio Barros de Castro - Sem nosso potencial em produtos primários, em longo prazo estaríamos numa situação dificílima.

Mas hoje temos três bons problemas: segurar o balanço de pagamentos por 10 ou 15 anos com petróleo, outras matérias-primas e produtos agrícolas; manter a expansão do mercado interno colocando areia para limitar a sua ocupação por importações; e desenvolver o potencial industrial visando não otimizações, mas mudanças.

Não tem que melhorar, tem que mudar. Otimização a China faz melhor.

\section{Quando o sr. fala em colocar areia, significa proteção.}

Antonio Barros de Castro - Não estou reproduzindo o discurso de que é atrasado proteger. O que digo é que não adianta proteger quando sua produtividade cresce mais devagar do que a do concorrente.

Um produtor de válvula brasileiro, por exemplo, está condenado. Ele sabe que pode não morrer hoje, mas morre no próximo governo.

É necessário conter as importações não para que algumas indústrias sobrevivam, mas para que possam ser transformadas. 


\section{Em que casos apostar?}

Esse mapa completo ainda deve ser feito. Seriam setores protegidos pela especificidade dos nossos recursos naturais, por costumes, estrutura industrial e demanda. Áreas em que o chinês não está nem vai estar.

Não proponho uma volta ao agrário. O agrário é uma trégua para você, por exemplo, construir uma indústria ligada ao pré-sal, de satélites, de novos materiais, de aços especiais. É aplicar os conhecimentos existentes para desenvolver coisas próprias e originais.

A química do etanol permite desenvolver plásticos verdes. A indústria automobilística chinesa deseja vir para cá? Vamos fazer um acordo para em dez anos os plásticos serem todos verdes; nós garantimos a evolução do produto. É usar a China como mercado.

É possível mudar os tratores para que eles se adaptem às necessidades do Brasil. Não é pegar o americano e fazer outro um pouco mais sofisticado. É fazer máquinas adaptadas às condições tropicais de solo, clima.

O embaixador chinês, respondendo às críticas ao câmbio desvalorizado do país, disse que cabe ao Brasil se tornar mais competitivo. Ele está certo?

Antonio Barros de Castro - Os chineses acham que se a gente trabalhar mais e for mais sério não teremos problemas. Não é isso, é uma questão de estratégia.

\section{A indústria reclama do câmbio e do custo Brasil (impostos, infraestrutura). Há alguma razão nisso?}

Antonio Barros de Castro - Se o câmbio e o custo Brasil forem neutros, boa parte da indústria brasileira não é competitiva porque o sistema industrial chinês é mais eficiente. Até 2004, eles já arrombavam todos os mercados e não tinham câmbio desvalorizado. Alega-se que antes os produtos chineses eram só mais baratos, porque o salário era ínfimo e a fábrica era um galpão velho. Mas agora são boas fábricas e amanhã serão excelentes. A produtividade sobe tão rápido que, mesmo com a alta dos salários, os produtos ainda podem custar menos. O real está sobrevalorizado? Claro, sou $100 \%$ a favor de botar areia no câmbio. Agora, ou você enfrenta as causas da nossa perda relativa de competitividade ou não vai a lugar nenhum. 